\title{
New Topologies of Lossless Grounded Inductor Using OTRA
}

\author{
Rajeshwari Pandey, ${ }^{1}$ Neeta Pandey, ${ }^{1}$ Sajal K. Paul, ${ }^{2}$ A. Singh, ${ }^{1}$ \\ B. Sriram, ${ }^{1}$ and K. Trivedi ${ }^{1}$ \\ ${ }^{1}$ Department of Electronics and Communication, Delhi Technological University, Bawana Road, Delhi 110042, India \\ ${ }^{2}$ Department of Electronics Engineering, Indian School of Mines, Dhanbad 826004, India
}

Correspondence should be addressed to Sajal K. Paul, sajalkpaul@rediffmail.com

Received 28 March 2011; Revised 14 June 2011; Accepted 14 June 2011

Academic Editor: Raj Senani

Copyright (C) 2011 Rajeshwari Pandey et al. This is an open access article distributed under the Creative Commons Attribution License, which permits unrestricted use, distribution, and reproduction in any medium, provided the original work is properly cited.

Two alternate topologies of lossless grounded inductor have been proposed using operational transresistance amplifier (OTRA). Three applications using the proposed inductors are also included. PSPice simulation and experimental results have been included to demonstrate the performance and verify the theoretical analysis.

\section{Introduction}

Recently the operational transresistance amplifier (OTRA) has emerged as alternate important analog building block as it inherits all the advantages offered by current mode techniques. The OTRA is a high-gain current input voltage output device. The input terminals of OTRA are internally grounded, thereby eliminating response limitations due to parasitic capacitances and resistances at the input. Although the OTRA is commercially available from several sources under the name of current differencing amplifier or Norton amplifier, it has not gained attention until recently. These commercial realizations do not provide internal ground at the input port and allow the input current to flow in one direction only. The former disadvantage limits the functionality of the OTRA where as the later forces to use external DC bias current leading to complex and unattractive designs [1]. Several high-performance CMOS OTRA topologies have been proposed in literature [1-4] leading to growing interest in OTRA-based analog signal processing circuits. In the recent past OTRA has been extensively used as an analog building block for realizing a number of signal processing circuits such as filters [5-8], oscillators $[9,10]$, multivibrators $[11,12]$, and immittance simulation circuits $[9,13-15]$, an application which has been dealt with in this paper. A number of grounded parallel immittance topologies using single OTRA are proposed in [13]. However none of these configurations can realize a lossless grounded inductor. The structure in [14] presents simulation of lossless negative grounded inductance. Lossless grounded inductor simulators using two OTRAs, five resistors, and one capacitor are presented in $[9,15]$.

In this paper two additional topologies of lossless grounded inductor using two OTRAs, five resistors, and one capacitor are reported. In these topologies five passive elements out of six are grounded as compared to four grounded elements in $[9,15]$. Some applications of the proposed topologies are also presented.

\section{Circuit Description}

OTRA is a three-terminal device, shown symbolically in Figure 1 and its port relations can be characterized by the following matrix:

$$
\left[\begin{array}{c}
V_{p} \\
V_{n} \\
V_{O}
\end{array}\right]=\left[\begin{array}{ccc}
0 & 0 & 0 \\
0 & 0 & 0 \\
R_{m} & -R_{m} & 0
\end{array}\right]\left[\begin{array}{c}
I_{p} \\
I_{n} \\
I_{O}
\end{array}\right] .
$$

For ideal operations the transresistance gain $R_{m}$ approaches infinity and forces the input currents to be equal. Thus OTRA must be used in a negative feedback configuration.

The proposed lossless grounded inductor topologies are shown in Figure 2. Routine analysis of the circuit of 


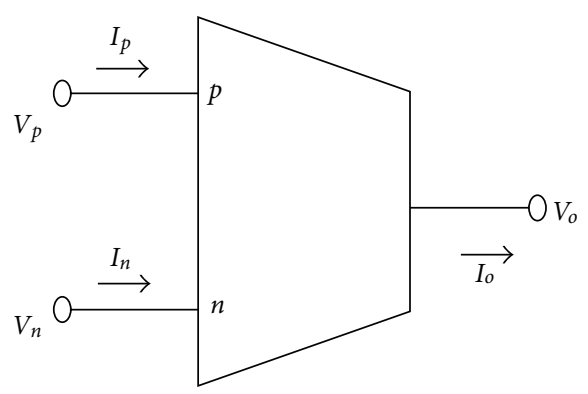

FIgURE 1: OTRA circuit symbol.

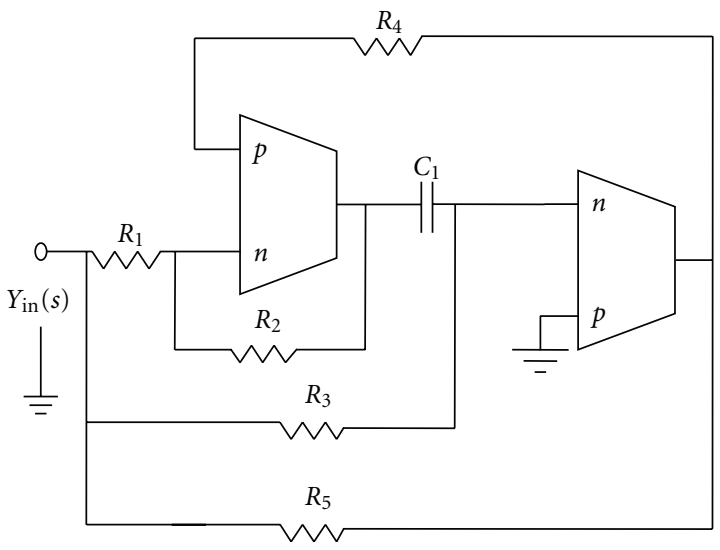

(a)

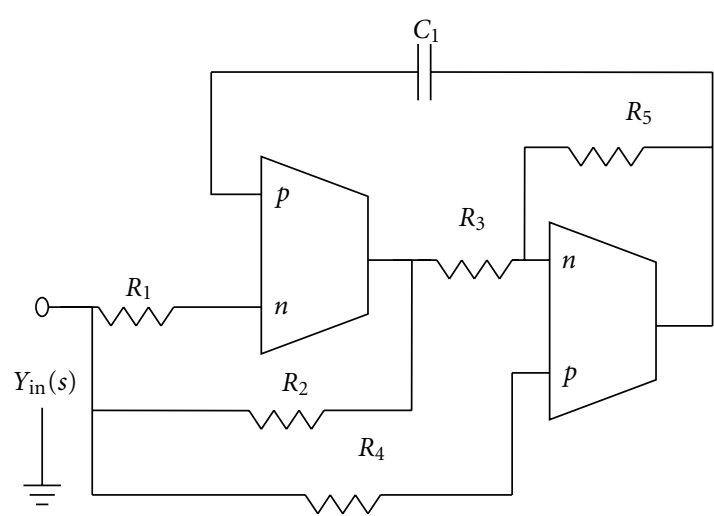

(b)

Figure 2: Inductor simulation topologies.

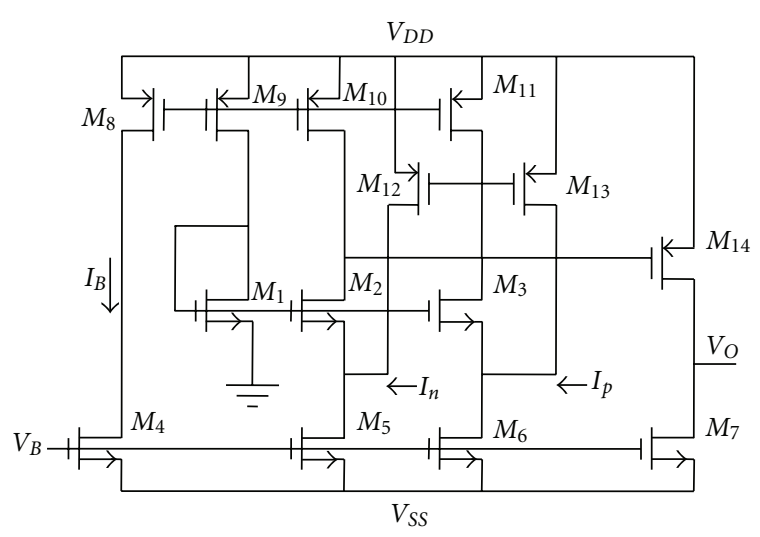

FIGURE 3: CMOS implementation of OTRA [4].

Figure 2(a) results in the following expression for input admittance:

$$
Y_{\text {in }}(s)=\left(G_{1}+G_{3}+G_{5}-\frac{G_{1} G_{5}}{G_{4}}\right)+\frac{C_{1} G_{4}}{s G_{2} G_{3} G_{5}},
$$

$Y_{\text {in }}$ will be purely inductive if the following condition is met

$$
G_{1}+G_{3}+G_{5}=\frac{G_{1} G_{5}}{G_{4}} .
$$

Similarly for inductor topology of Figure 2(b), input admittance is given by

$$
Y_{\text {in }}(s)=\left(G_{1}+G_{2}+G_{4}-\frac{G_{2} G_{4}}{G_{3}}\right)+\frac{C_{1} G_{3}}{s G_{1} G_{2} G_{5}} .
$$

This input admittance will be purely inductive provided that

$$
G_{1}+G_{2}+G_{4}=\frac{G_{2} G_{4}}{G_{3}} .
$$

The equivalent inductance values along with conditions are given in Table 1.

It is clear from Table 1 that for both the topologies the inductance value can be controlled independent of condition of realization.

The proposed topologies are verified through simulations using the CMOS implementation of the OTRA [4] as given in Figure 3. The SPICE simulation is performed using $0.5 \mu \mathrm{m}$ CMOS process parameters provided by MOSIS (AGILENT) and supply voltages taken are $\pm 1.5 \mathrm{~V}$. Aspect ratios used for different transistors are given in Table 2.

An inductor of value $L_{\mathrm{eq}}=0.1 \mathrm{mH}$ is designed using the inductor topology of Figure 2(a) with the component values of $R_{1}=R_{2}=R_{3}=R_{5}=1 \mathrm{~K} \Omega, R_{4}=3 \mathrm{~K} \Omega, C_{1}=300 \mathrm{pF}$. The frequency response of the impedance as obtained using this inductor is shown in Figure 4(a). The inset depicts the enlarged view of impedance response in lower frequency range. 
TABLE 1: Inductors realized by the topologies shown in Figure 2.

\begin{tabular}{llll}
\hline Figure & Condition & $L_{\mathrm{eq}}$ & $\begin{array}{l}\text { Non-interactive } \\
\text { control of } L_{\mathrm{eq}}\end{array}$ \\
\hline Figure 2(a) & $G_{1}+G_{3}+G_{5}=\frac{G_{1} G_{5}}{G_{4}}$ & $\frac{C_{1} G_{4}}{G_{2} G_{3} G_{5}}$ & $\begin{array}{l}\text { Independent control } \\
\text { of value of } L_{\mathrm{eq}} \\
\text { through } G_{2}\end{array}$ \\
\hline Figure 2(b) & $G_{1}+G_{2}+G_{4}=\frac{G_{2} G_{4}}{G_{3}}$ & $\frac{C_{1} G_{3}}{G_{1} G_{2} G_{5}}$ & $\begin{array}{l}\text { Independent control } \\
\text { of value of } L_{\mathrm{eq}} \\
\text { through } G_{5}\end{array}$ \\
\hline
\end{tabular}

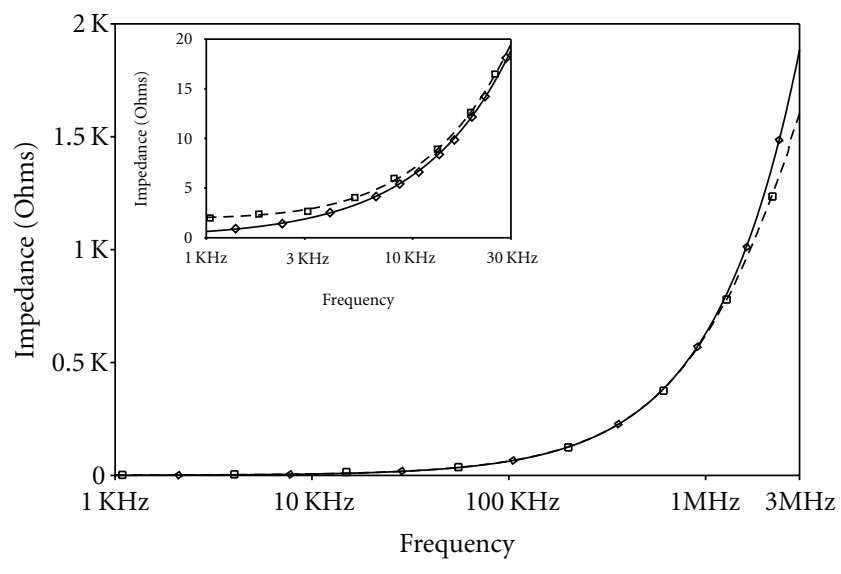

— Ideal

(a)

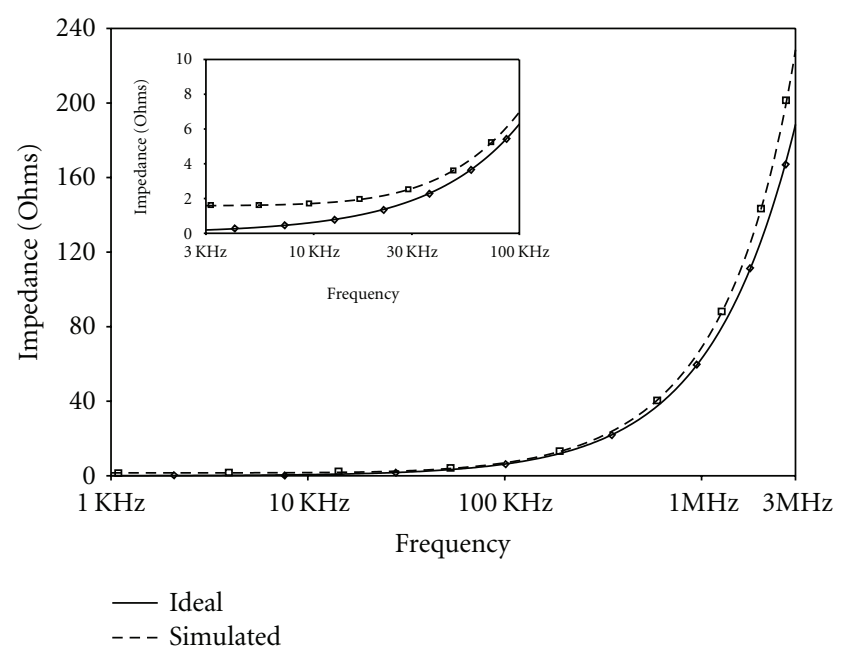

(b)

FIGURE 4: (a) Impedance versus frequency response of topology of Figure 2(a). (b) Impedance versus frequency response of topology of Figure 2(b).

TABLE 2: Aspect ratio of the transistors.

\begin{tabular}{lc}
\hline Transistor & $W(\mu \mathrm{m}) / L(\mu \mathrm{m})$ \\
\hline $\mathrm{M}_{1}-\mathrm{M}_{3}$ & $100 / 2.5$ \\
$\mathrm{M}_{4}$ & $10 / 2.5$ \\
$\mathrm{M}_{5}, \mathrm{M}_{6}$ & $30 / 2.5$ \\
$\mathrm{M}_{7}$ & $10 / 2.5$ \\
$\mathrm{M}_{8}-\mathrm{M}_{11}$ & $50 / 2.5$ \\
$\mathrm{M}_{12}, \mathrm{M}_{13}$ & $100 / 2.5$ \\
$\mathrm{M}_{14}$ & $50 / 0.5$ \\
\hline
\end{tabular}

Similarly, Figure 4(b) shows the frequency response of the impedance of the inductor of value $L_{\mathrm{eq}}=10 \mu \mathrm{H}$ as obtained with component values of $R_{1}=R_{2}=R_{4}=R_{5}=$ $1 \mathrm{~K} \Omega, R_{3}=3 \mathrm{~K} \Omega$, and $C_{1}=30 \mathrm{pF}$ for inductor topology given in Figure 2(b). In the inset, the variation of impedance in lower frequency range is shown.

\section{Applications}

In this section some applications of the proposed topologies have been presented. Both the topologies may be used for constructing filter and oscillator circuits.
3.1. High-pass Filter. A high pass filter, as shown in Figure 5(a), can be constructed using proposed inductors. The transfer function for high pass response is obtained as

$$
\frac{V_{o}}{V_{\text {in }}}=\frac{s^{2}}{s^{2}+s / C R+1 / L_{\mathrm{eq}} C},
$$

where

$$
\omega_{0}=\frac{1}{\sqrt{ }\left(L_{\mathrm{eq}} C\right)}, \quad Q=R \sqrt{ }\left(\frac{C}{L_{\mathrm{eq}}}\right) .
$$

The functionality of the high pass filter is verified using the inductor topology of Figure 2(a) and designed for lower cutoff frequency of $503.3 \mathrm{KHz}$. The component values are obtained as $R=300 \Omega$ and $C=1 \mathrm{nF}$ for $L_{\mathrm{eq}}=0.1 \mathrm{mH}$. The value of $L_{\mathrm{eq}}=0.1 \mathrm{mH}$ is obtained using inductor topology of Figure 2(a) with component values of $R_{1}=$ $R_{2}=R_{3}=R_{5}=1 \mathrm{~K} \Omega, R_{4}=3 \mathrm{~K} \Omega$, and $C_{1}=300 \mathrm{pF}$. The frequency response of the filter simulated using PSPICE is depicted in Figure 5(b). Simulated value of lower cutoff frequency is obtained as $505 \mathrm{KHz}$ which is in close agreement to the theoretical value of $503.2 \mathrm{KHz}$.

3.2. Band Pass Filter. The proposed inductor topologies may also be used to obtain band-pass response using the circuit 


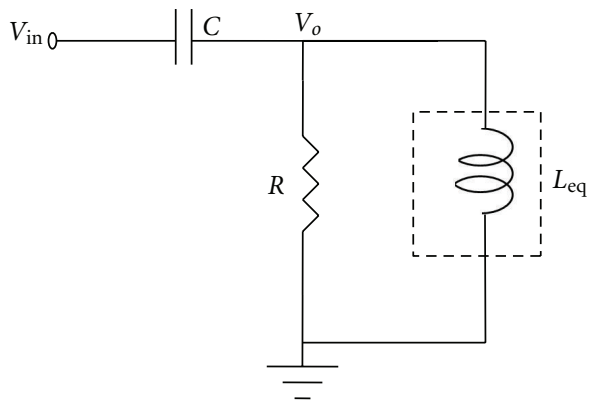

(a)

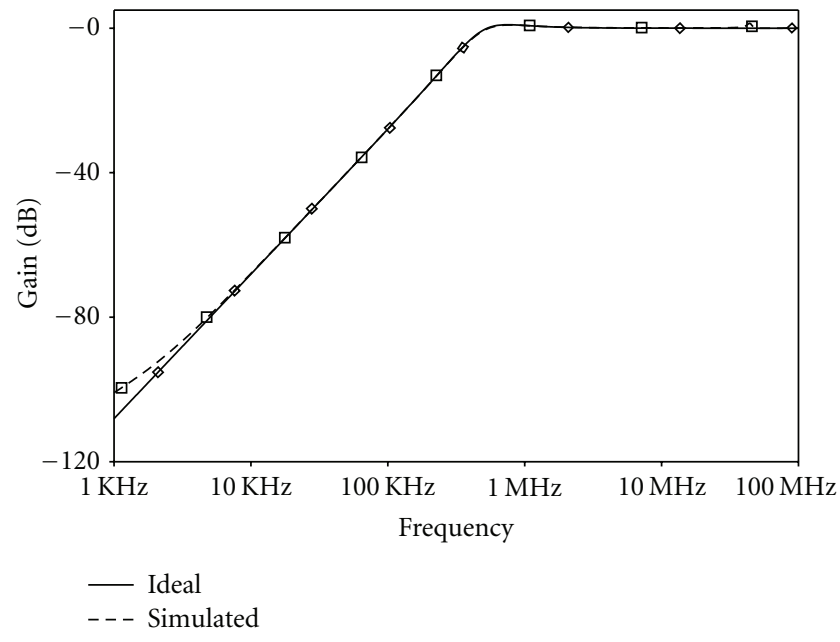

(b)

FIgURE 5: (a) High-pass filter. (b) Frequency response of high pass filter.

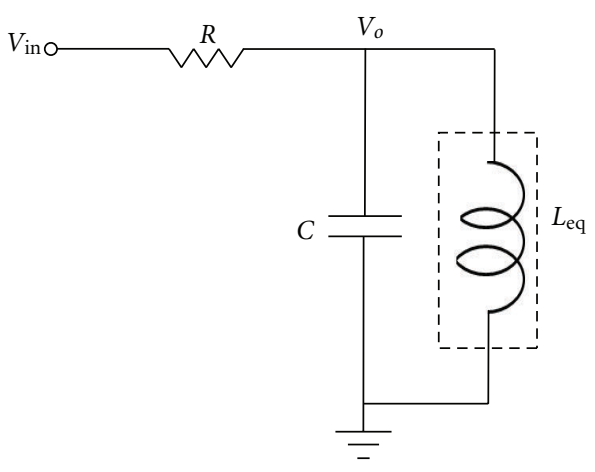

(a)

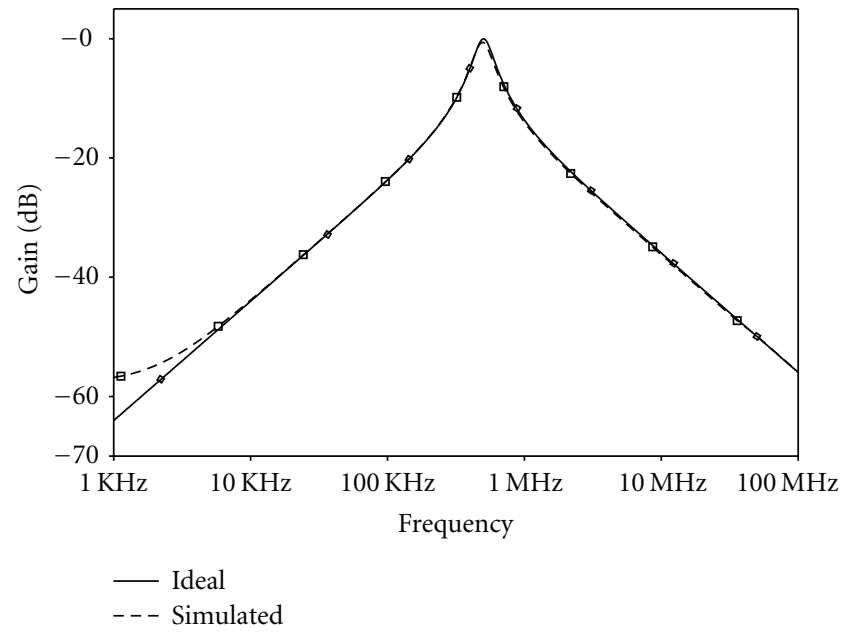

(b)

Figure 6: (a) Band-pass filter. (b) Frequency response of band-pass filter.

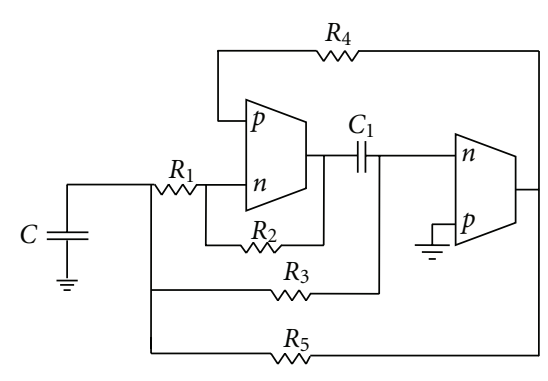

(a)

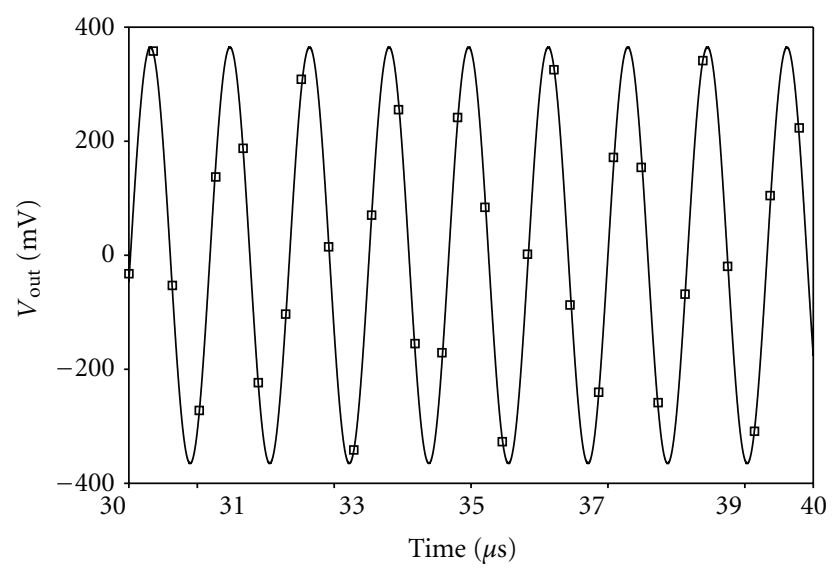

(b)

FIgURe 7: (a) LC oscillator. (b) Output of LC oscillator. 


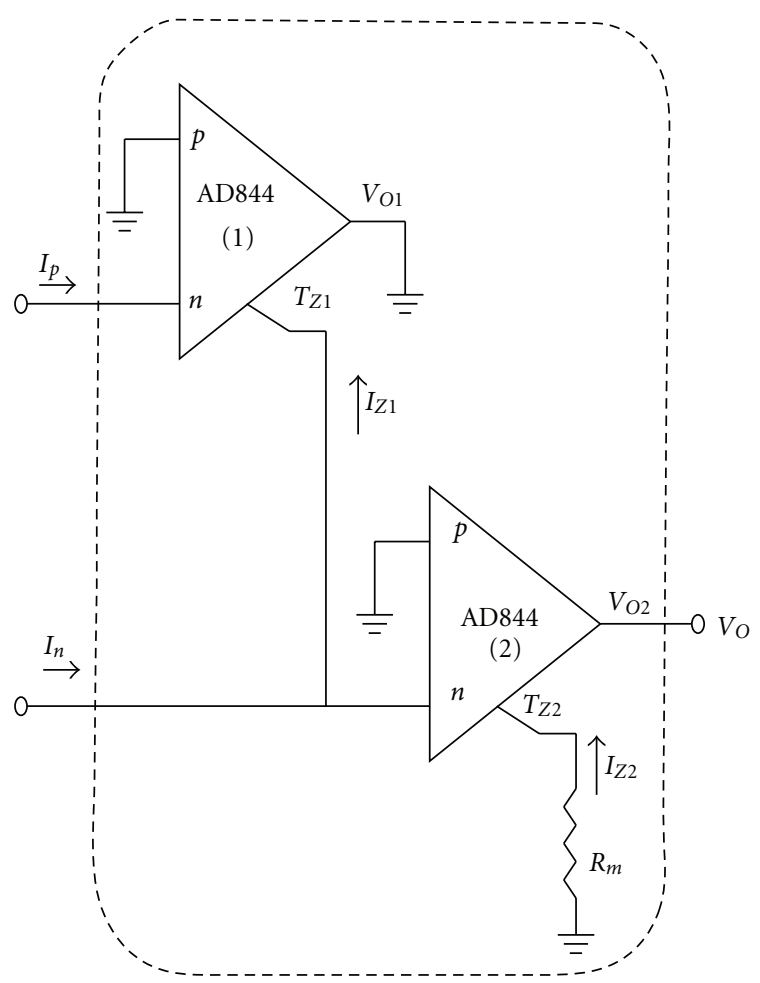

Figure 8: CFOA based OTRA implementation.

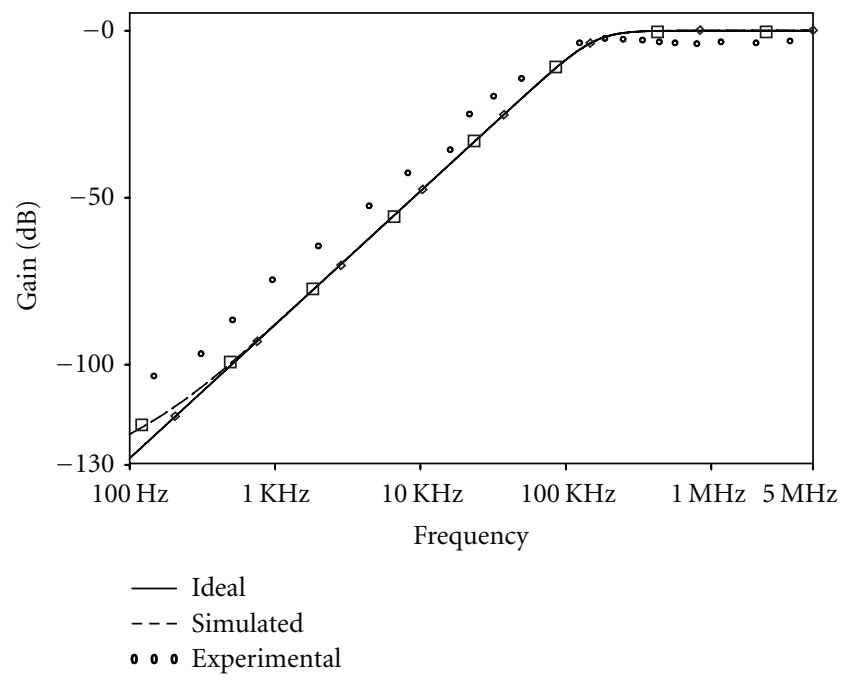

FIgURE 9: Frequency response of the high-pass filter.

given in Figure 6(a). The transfer function for band-pass response is obtained as

$$
\frac{V_{o}}{V_{\text {in }}}=\frac{s / C R}{s^{2}+s / C R+1 / L_{\mathrm{eq}} C},
$$

where

$$
\omega_{0}=\frac{1}{\sqrt{ }\left(L_{\mathrm{eq}} C\right)}, \quad Q=R \sqrt{\left(\frac{C}{L_{\mathrm{eq}}}\right)} .
$$

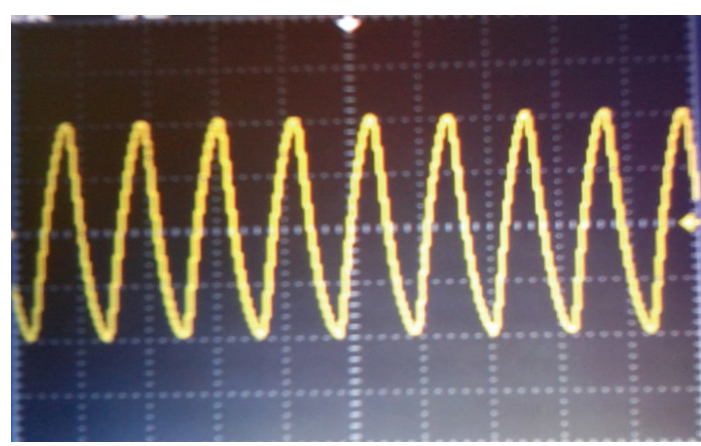

FIgURE 10: Experimental output of LC oscillator.

The theoretical proposition is verified using the topology of Figure 2(b). A band-pass filter is designed having center frequency of $503.3 \mathrm{KHz}$. The component values are obtained as $R=1 \mathrm{~K} \Omega$ and $C=1 \mathrm{nF}$ for $L_{\mathrm{eq}}=0.1 \mathrm{mH}$. The value of $L_{\mathrm{eq}}=0.1 \mathrm{mH}$ is obtained for inductor topology of Figure 2(b) with component values of $R_{1}=R_{2}=$ $R_{4}=R_{5}=1 \mathrm{~K} \Omega, R_{3}=3 \mathrm{~K} \Omega, C_{1}=300 \mathrm{pF}$. The frequency response of the filter simulated using PSPICE is depicted in Figure 6(b). The simulated results are in close agreement with the theoretical prediction.

3.3. LC Oscillator. An LC Oscillator can be realized using the proposed inductor topologies. Figure 7(a) shows the schematic of an LC oscillator using topology of Figure 2(a) for which the condition of oscillation (CO) and frequency of oscillation (FO) are obtained as

$$
\begin{gathered}
\mathrm{CO}: G_{1}+G_{3}+G_{5}=\frac{G_{1} G_{5}}{G_{4}}, \\
\mathrm{FO}: f_{o}=\frac{1}{2 \prod \sqrt{C C_{1} R_{2} R_{3} R_{5} / R_{4}}} .
\end{gathered}
$$

Figure 7(b) shows the output of the oscillator for $L_{\mathrm{eq}}=$ $0.1 \mathrm{mH}$ and $C=330 \mathrm{pF}$. Simulated frequency of oscillation is $860 \mathrm{KHz}$ as against the calculated value of $876.2 \mathrm{KHz}$ with $\%$ error of $1.85 \%$.

3.4. Experimental Verification. The proposed inductor topologies are also tested experimentally to verify the theory. The OTRA is implemented using two CFOAs (IC AD844AN) as shown in Figure 8 with a supply voltage of $\pm 5 \mathrm{~V}$.

The high pass filter of Figure $5(\mathrm{a})$ is prototyped with $C=1 \mathrm{nF}, R=680 \Omega$, and $L_{\mathrm{eq}}=1 \mathrm{mH}$. The inductor of value $L_{\mathrm{eq}}=1 \mathrm{mH}$ is implemented using inductor topology of Figure 2(a) with component values of $R_{1}=R_{2}=$ $R_{3}=R_{5}=1 \mathrm{~K} \Omega, R_{4}=3 \mathrm{~K} \Omega$, and $\mathrm{C}_{1}=3 \mathrm{nF}$. Theoretical, simulated and experimental frequency responses are shown in Figure 9. It is observed that the experimental values more or less follow the theoretical and simulated values. The oscillator circuit of Figure $7(\mathrm{a})$ is also tested experimentally. The output waveform observed on oscilloscope is shown in Figure 10. The observed frequency of oscillation is found to be $872.5 \mathrm{KHz}$, which is in close agreement to theoretically calculated value of $876.2 \mathrm{KHz}$. 


\section{Conclusion}

Two new OTRA-based lossless grounded inductor topologies are presented. A high pass filter, band-pass filter, and an oscillator are realized using the proposed inductor topologies to illustrate their applications. PSpice simulation and experimental results are included to verify the theoretical propositions. It is found that the results obtained are in close agreement with the ideal values. Hence it is expected that the proposed inductors will provide an option to integrated circuit designer where lossless grounded inductor is required.

\section{References}

[1] N. Salama and A. M. Soliman, "CMOS OTRA for analog signal processing applications," Microelectronics Journal, vol. 30, pp. 235-245, 1999.

[2] J. J. Chen, H. W. Tsao, and C. C. Chen, "Operational transresistance amplifier using CMOS technology," Electronics Letters, vol. 28, no. 22, pp. 2087-2088, 1992.

[3] H. Mostafa and A. M. Soliman, "A modified CMOS realization of the operational transresistance amplifier (OTRA)," Frequenz, vol. 60, no. 3-4, pp. 70-76, 2006.

[4] A. K. Kafrawy and A. M. Soliman, "A modified CMOS differential operational transresistance amplifier (OTRA)," AEUInternational Journal of Electronics and Communications, vol. 63, no. 12, pp. 1067-1071, 2009.

[5] S. Kilinç and U. Çam, "Cascadable allpass and notch filters employing single operational transresistance amplifier," Computers and Electrical Engineering, vol. 31, no. 6, pp. 391-401, 2005.

[6] C. Cakir, U. Çam, and O. Cicekoglu, "Novel allpass filter configuration employing single OTRA," IEEE Transactions on Circuits and Systems II, vol. 52, no. 3, pp. 122-125, 2005.

[7] J. J. Chen, H. W. Tsao, S. I. Liu, and W. Chiu, "Parasiticcapacitance-insensitive current-mode filters using operational transresistance amplifiers," IEE Proceedings: Circuits, Devices and Systems, vol. 142, no. 3, pp. 186-192, 1995.

[8] A. Gokcen and U. Çam, "MOS-C single amplifier biquads using the operational transresistance amplifier," $A E U$ International Journal of Electronics and Communications, vol. 63, no. 8, pp. 660-664, 2009.

[9] K. N. Salama and A. M. Soliman, "Novel oscillators using the operational transresistance amplifier," Microelectronics Journal, vol. 31, no. 1, pp. 39-47, 2000.

[10] U. Çam, "A novel single-resistance-controlled sinusoidal oscillator employing single operational transresistance amplifier," Analog Integrated Circuits and Signal Processing, vol. 32, no. 2, pp. 183-186, 2002.

[11] C. L. Hou, H. C. Chien, and Y. K. Lo, "Squarewave generators employing OTRAs," IEE Proceedings: Circuits, Devices and Systems, vol. 152, no. 6, pp. 718-722.

[12] Y. K. Lo, H. C. Chien, and H. J. Chiu, "Switch-controllable OTRA-based bistable multivibrators," IET Circuits, Devices and Systems, vol. 2, no. 4, pp. 373-382, 2008.

[13] U. Çam, F. Kaçar, O. Cicekoglu, H. Kuntman, and A. Kuntman, "Novel grounded parallel immittance simulator topologies employing single OTRA," AEU-International Journal of Electronics and Communications, vol. 57, no. 4, pp. 287-290, 2003.
[14] S. Kilinç, K. N. Salama, and U. Çam, "Realization of fully controllable negative inductance with single operational transresistance amplifier," Circuits, Systems, and Signal Processing, vol. 25, no. 1, pp. 47-57, 2006.

[15] U. Çam, F. Kaçar, O. Cicekoglu, H. Kuntman, and A. Kuntman, "Novel two OTRA-based grounded immitance simulator topologies," Analog Integrated Circuits and Signal Processing, vol. 39, no. 2, pp. 169-175, 2004. 

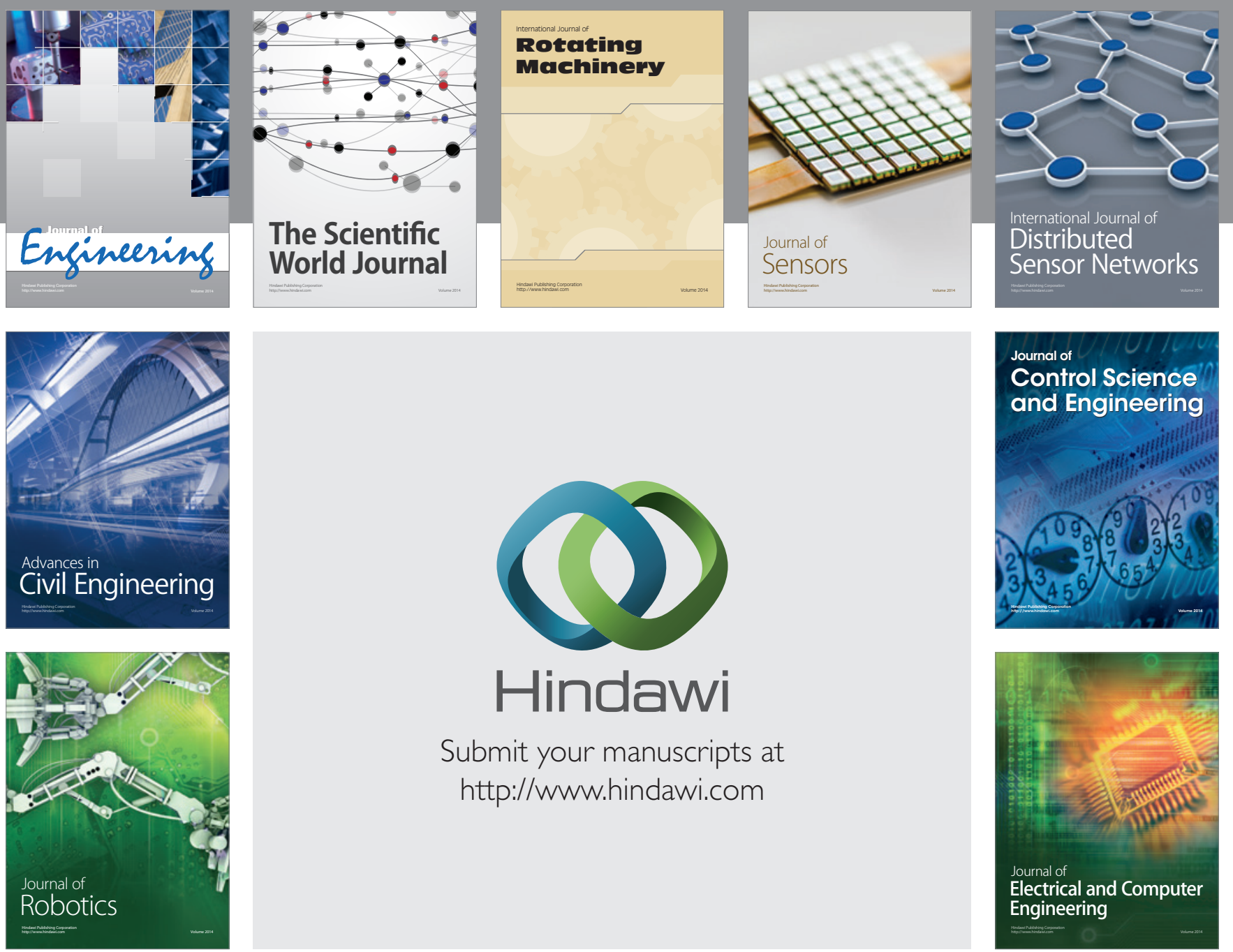

Submit your manuscripts at

http://www.hindawi.com
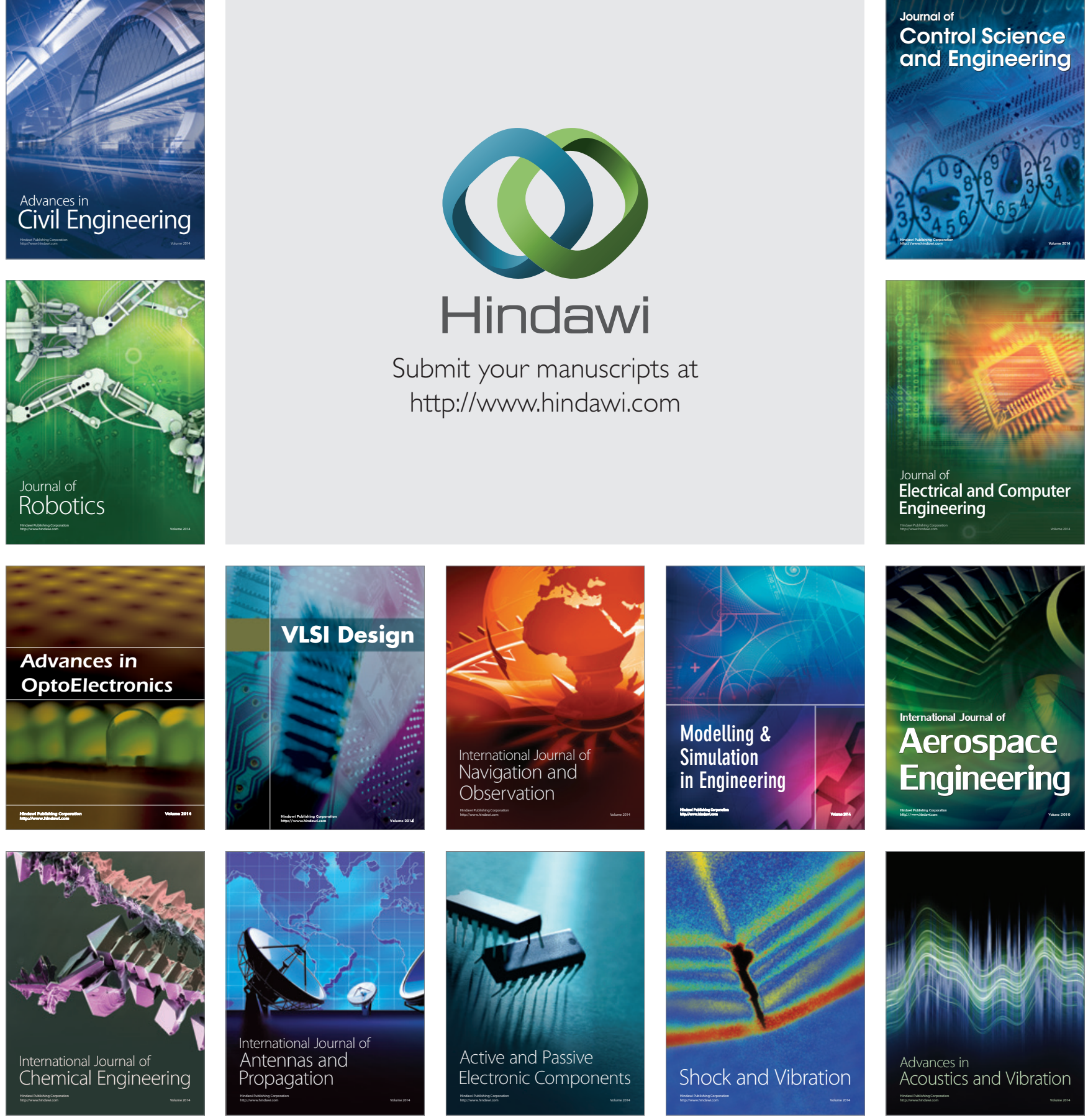